\title{
Vida e obra de Alberto Osório de Castro em Timor
}

Vicente Paulino

Universidade Nacional Timor Lorosa'e

CEMRI - Universidade Aberta de Lisboa

CLEPUL - Universidade de Lisboa

DOI: https://doi.org/10.31492/2184-2043.RILP2019.36/pp.57-74

\begin{abstract}
Resumo
Neste artigo pretendemos explorar descritivamente a presença do jurista e poeta Alberto Osório de Castro em Timor, terra longínqua do extremo oriente. Num primeiro momento, apresentamos a sua infância, passagem pela Coimbra e Mangualde e respectiva participação nas revistas literárias como correspondente e autor, no qual publicou vários estudos literários, poemas, crónicas de história e de viagem. Num segundo momento, focamo-nos na sua estadia em Timor como juiz, bem como observamos algumas das principais obras associadas à ilha de Timor e sua gente com culturas diferenciadas, nomeadamente as Flores de Coral e A Ilha Verde e Vermelha de Timor, resultante de uma aproximação a estas obras mediada pela perspectiva dos estudos em literatura e apreciação exótica da paisagem orientalista no mundo timorense que se norteia pelas cores da gente.
\end{abstract}

Palavras-chaves: Alberto Osório de Castro; Timor; Flores de Coral; Oriente; estudos literários.

\section{Abstract}

In this article we intend to explore descriptively the presence of the lawyer and poet Alberto Osorio de Castro who was in Timor, far-off land of Far East. At first, we present his childhood, passing through Coimbra and Mangualde and their participation in literary magazines as a correspondent and author, in which he published several literary studies, poems, chronicles of history and travel. Secondly, we focus on your stay in Timor as judge and observe some of the major works associated with the island of Timor and its people with different cultures, including Coral Flower and The Red and Green Island of Timor, resulting from an approach to these works mediated by the prospect of literature studies and exotic orientalist landscape appreciation of the Timorese world that is guided by the colors of people.

Keywords: Alberto Osório de Castro; East Timor; Coral Flowers; Orient; literary studies.

\section{Prólogo}

Alberto Osório de Castro, nascido no dia 1 de Março de 1868 na cidade de Coimbra, faleceu em 1 de Janeiro de 1946 - Lisboa. Filho do Dr. João Baptista de Castro e D. Mariana de Castro Cabral e Albuquerque Moore Hincio. Teve três irmãos: Ana, João e Jerônimo (cf. Goldsteins, 2012, p. 11). Apesar de ter nascido em Coimbra, passou a sua infância em companhia dos pais em Mangualde (uma vila que naquela altura pertencia ao conselho de Viseu, actualmente goza do estatuto de 'Município'). Neto do antigo governador de Macau, José Osório de Castro Cabral de Albuquerque ${ }^{1}$.

${ }^{1}$ Fonte: http://easttimorlinguistics.blogspot.com/2011/07/ilha-verde-e-vermelha-de-timor.html (acesso em 28/4/2014). 
Aos dez anos de idade, especificamente em 1878, matriculou-se na Escola Académica de Lisboa e ficou a residir na casa da sua tia, Maria Cândida Fonseca Mangas. Só regressava à casa dos pais nos meses de férias. Alberto era conhecido como um menino de talento e criativo, tendo conseguido relatar a sua experiência de vida na infância num pequeno diário intitulado "A minha vida" (cf. Goldsteins, 2012, p. 12). É portanto a partir de seus textos poéticos que é possível conhecer a infância de Alberto Osório de Castro. O timbre lírico sobre a sua infância e Portugal está bem aclamado em "Febre D'exílio", o seu primeiro poema de Exiladas (Castro, 1994, p. 53):

\footnotetext{
Fui enfermiço e tive uma pálida infância.

Doce, faltou-me sempre a viril arrogância

Fraco, com uma pobre infância muito breve,

Sempre doente, a fazer castelo infinito.
}

Aos 21 anos formou-se em Direito pela Universidade de Coimbra e começou a assumir a sua profissão como juiz municipal de Óbidos. Foi juiz nas antigas províncias ultramarinas portuguesas na Índia, em Angola e em Timor. Após regressar ao continente português, exerceu as funções de juiz do Supremo Tribunal de Justiça e foi presidente do Conselho Superior de Administração Pública. Foi Dirigente da Federação Nacional Republicana. Ligado a Machado Santos, assume-se como sidonista; e ainda assumiu a pasta de Ministro da Justiça (de 15 de Maio a 8 de Outubro de 1918) no governo de Sidónio Pais. Promoveu o reatamento das relações diplomáticas de Portugal com a Santa Sé e foi responsável pela instalação do Tribunal da Relação de Coimbra. Assegurou o direito das vítimas de acidentes em transportes à reparação dos prejuízos sofridos. Foi ajudante de conservador às mulheres formadas em Direito. Criou uma comissão para organização do trabalho agrícola dos reclusos. Regulamentou o Arquivo de Identificação e a emissão do Bilhete de Identidade².

Nas letras, esteve ligado ao nascimento da revista Boémia Nova - Revista de Literatura Sciencia (criada em Fevereiro de 1889 que chega a seu fim em Abril do mesmo ano $)^{3}$. Foi nesta revista que estreou-se no campo da poesia com a publicação Exiladas em 1895.

\footnotetext{
${ }^{2}$ Fonte: http://primeirarepublica.mj.gov.pt/Paginas/alberto-osorio-de-castro.aspx (acesso em 28/4/2014).

3 Ao mesmo tempo, com esta revista que se estabeleceu o seu primeiro contacto com a arqueologia. Nesta redacção recebia-se também a Revista de Guimarães (órgão da Sociedade Martins Sarmento e um dos importantes periódicos com artigos de índole arqueológica). Ao lê-la ficou surpreendido, pois, como refere na $1 .^{\mathrm{a}}$ carta que enviou a Francisco Martins Sarmento, Imaginava que em Portugal seria impossível encontrar, e de mais a mais vinda do fundo da província, uma publicação daquela ordem. Em meio de uma população fútil e palreira
} 
Politicamente foi um dos membros do Partido Centrista Republicano e presidente da Direcção do Centro/Grémio Centrista de Lisboa. Foi homem de literatura e foi nesse sentido que considerado como um dos grandes da "literatura portuguesa". Esteve em Timor, ao princípio do século XX. Nesta terra longínqua desempenhou as funções de Juiz de Direito da Comarca. Escritor e poeta de grande merecimento. Dedicou-se também ao jornalismo político, tendo fundado, com Alves Boçadas, na Índia, o Oriente Português ${ }^{4}$. No caso concreto de Timor Português, Alberto Osório de Castro e Carlos Cal Brandão pretendiam "desenvolver a actividade cultural na área de comunicação, nunca o puderam fazer porque não havia condições objectivas e materiais para isso" (Paulino, 2011, p. 170; Paulino, 2012, p. 125).

Enfim, o interesse do Alberto Osório de Castro pelo "Oriente Português" parece que foi uma das "saudades inspiradas" em "algumas lembranças" herdadas pela sua avó materna que passava nas terras orientais, como dizia o poeta: "Das saudades dela fiz saudades minhas" (Castro, 1996, p. 17). Essa sua saudade foi revelada poeticamente em versos "Doçarias do Passado" (Castro, 1996, p. 17):

\footnotetext{
Tenho de minha avó receitinhas caseiras

Que dizem a saudade e o gosto da exilada;

Acepipes gentis, doçarias ligeiras,

Do queimor da sua terra olente e nacarada.

(...)

Lá vêm pudins, «àluá», o «panicuque» forte

Que às crianças daria o vigor dos Avós,

$\mathrm{E}$ os «genetes» que têm cuidadoso recorte...

De tudo isso veio um suco para nós

Onde floriram os jardins da sua infância?

Jardins coloniais de crótones, jasmins!

Como a saudade vai a tamanha distância,

E como sempre lembra o olor dos mogarins!...
}

\footnotetext{
de jornalistas e de bacharéis baclés, espanta ver um sábio da estatura do descobridor da Citânia, do autor dos Argonautas, e uma associação cientifica de primeira ordem como a Sociedade Martins Sarmento (Nóbrega, 2004).

${ }^{4} \mathrm{O}$ existencialismo do "Oriente Português" foi aclamado por escritores e poetas que alguma vez pisaram os pés nas terras asiáticas, tais como Luís de Camões, Fernão Mendes Pinto, Manuel Maria Barbosa du Bocage, António Patrício, Camilo Pessanha, Alberto Osório de Castro, Venceslau de Morais e, mais recentemente, Ruy Cinatti, Armando Martins Janeira, António Manuel Couto Viana e José Augusto Seabra. Foram eles que constituíram a linhagem de autores que manifesta uma ligação simultaneamente vivencial e estética ao Oriente português. Esta tem vindo a depender sobretudo de funções diplomáticas e/ou representativas do Estado Português (desde o próprio Camões, que em Macau foi "provedor-mor de defuntos e ausentes" até ao diplomata José Augusto Seabra), do exercício do Direito e de outras funções outrora estreitamente ligadas ao aparelho colonial (Almeida \& Braga, 2013).
} 
É portanto a partir destes versos que começou estabelecer ou formar a sua "emotividade lírica". Certo é que os versos "Doçarias do Passado" representa, sobretudo, uma revelação interior que lhe dava razão para ir ao oriente, porque havia um certo gosto e um espírito curioso que ele tinha daquela época. Portanto para Alberto Osório de Castro a sua decisão de ir ao oriente foi "uma surpresa de saudade", pois em toda a sua descrição reconhece-se sempre o aroma delicadíssimo da natureza exótica das regiões visitadas, incluindo o adorável perfume natural escondido por completo na roupa suja e nos corpos sem banhos dos nativos que acabaram a bailar do tébedai (Castro, 1996, p. 57) debaixo de "Fulan naróma" (claridade da lua).

\section{A sua vida em Timor}

A sua vinda a Timor foi resultado de "ligações familiares", isto é, marcada pela passagem da avó materna de origem holandesa que nasceu em Batavia, e o percurso percorrido pelo avô paterno que foi juiz em Macau. Essa foi a herança familiar que levou o poeta ao Oriente e até ao Timor. E, pelo facto Alberto Osório de Castro esteve alguns anos em Goa, Moçamedes, Timor e em Luanda. Foi nestas terras longínquas que se realizou uma das suas mais caras aspirações, baseadas na leitura que ele fez durante da sua infância sobre a geografia universal. Parece que é a partir daí também que o poeta sentiu-se fascinado pelo Oriente e procurou conhecer mais perto possível.

O poeta procurou todos os meios para ir a Timor. A sua vinda a Timor surgiu quando ele assumiu o cargo juiz da comarca de Moçâmedes, tomou uma decisão e pediu transferência para Timor, onde permaneceu entre os anos de 1908 e 1911.

Pedi transferência para Timor, e houve a bondade no então Ministério do Ultramar de se atender a minha súplica, creio até que principalmente pelo argumento evocado do preço do caixão de ir à cova no cemiteriozinho de Moçãmedes, rodando à noite pelas hienas ou quimalancas do escuro deserto circundante. Fui, foi porventura, creio , o primeiro juiz colonial que requereu colocação em Timor (Castro, 1996, p. 14).

A razão principal que o levou a fazer o pedido de transferência foi a própria realidade africana que nada the agradou.

\footnotetext{
E na infinita desolação da costa atlântica a África austral, amortalhada rogo a meio do dia em taciturno cacimbo, eu só sonhava em tomar à resplandecente magia dos países do Oriente, ou, melhor ainda, do Extremo-Oriente. Vinham-me à lembrança gravuras admiradas na minha infância, ilustrando em $L e$ Tour du Monde a tradução francesa da obra do grande naturalista inglês Alfred Russel Wallace, The Malay Archipelago (Castro, 1996, p. 16).
}

Certo é que foi essa razão, e também pela sua autoconfiança, que o levou a viajar para Timor, prestando serviço jurídico ao governo colonial sediado naquele 
território. Foi assim que o poeta encontrou o seu "destino feliz", pois foi ali que encontrou o "cheiro do sândalo salutífero" profetizado por Luís de Camões. Entretanto, a sua primeira impressão foi impressionante, porque encontrava-se de novo perante a densa floresta coberta de palmeiras. Assim dizia ele:

\footnotetext{
A minha primeira impressão de Timor, no desembarque em Díli, foi a de que pisava de novo a terra da Índia do Conção, a Índia dos palmares.

A mesma cor vermelha do solo, aqui de xisto e suas argilas, lá de laterites, a mesma flora, a mesma tez da gente. Apenas aqui mais nacarada a luz mais docemente aproximada do sonho dos homens (Castro, 1996, p. 20).
}

Compreende-se que essa primeira impressão motivou o poeta a percorrer todo o território de Timor. Cada visita realizada dava-lhe novas ideias e novas aspirações, até que ele próprio reconheceu assim:

É estranho como esta natureza de Timor, vária e cintilante, em mim produz por vezes o mesmo grand songe terrestre, igual vertigem e ardente pânica à que me dão certos poemas de M.me de Noaille, de Henri de Régnier, de Gabriele D’Annunziol (Castro, 1996, p. 85).

Viver em Timor parecia que estar no paraíso, isto é, conviver com gentes simples, penetrando nas suas culturas e partilhando o mesmo sentido de vida. Assim que um malae vivenciou e praticou algumas danças dos timorenses em alguns eventos formais. O poeta Alberto Osório de Castro experienciou essa convivência tão harmoniosa com timorenses e participou algumas vezes nos bailes desse povo, como ele próprio descreveu em "Tebedai":

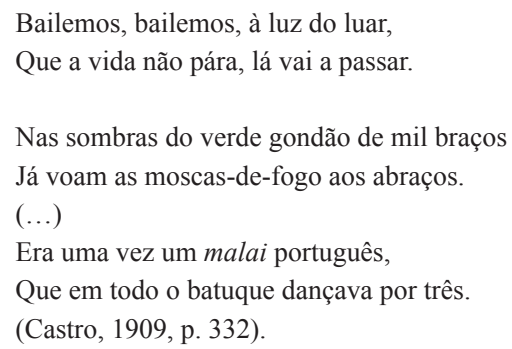

Ele revelou o "tebedai", o baile timorense, a partir das observações feitas nos bazares, nas festas populares e nas recepções dos administradores. Daí ele notou que "nas mulheres do tébedai de homenagem", como notou em "todos os batuques encontrados, uma grande frequência do bócio" (Castro, 1996, p. 56) onde os malaes também se divertiam com esse tipo de baile timorense. 


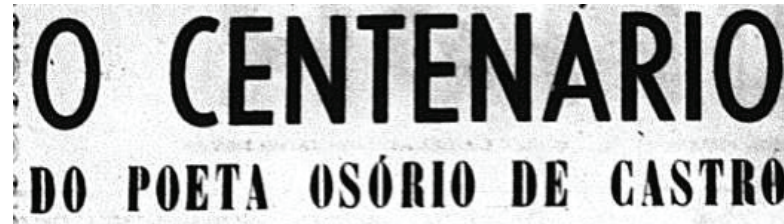

Latre os centealrlos qao eato ano decorrea e qae, directa on tadirecta meale, so eacontram Ilgados a gaa aetiridade caltaral portia ate relacioada coe - ultramar, campro-aos leabrar aqui o neee do poita slberto Ocório de Castre, nasoido en Coimbra. 4 sod dituacáo de motropolituno sio invalida, aen diminae 0 valor on saz obra. no que ela ba de estéticameato valido. a laso do ema lateate prosua. pa do temática oltramarias qae a di. mension a espace portagats ondo esto ve qae $\bullet$ inflacacion.

Bfoctivameate, slberto osirio do Costio, mal acabalo o sea carso de Direito, com 21 a aos, logo se onconira comeato pare oltranar, leado exercido a sta fancio do Maglatrado, on Ingola, va fadia o en finer. Istas proviacias torio represeatacia oa sua - obra do poeta e do investigador. Ista iria sargiado nos locais on qao resida. I assie a Crista dos Mirtoss sarge em Jova 6os, da mesma format quo allores do Coral, sargíra en Ti. aor, seado - primeiro irro ch impres so. Tamsea, esta provineia, Iho aotivara o notard trabalbo et itha Terdo - Termelha de Timars que a AgonciaGeral do Cltrumar editoa e quae, pronio, se obcantra esgotado. Seste ano ceateadrio do eseritor, nama das come- moraples que bosrario a saa memória, conta-a a reedipio desta obra, pela mesma Igincia Goral do Cltramar.

io momento da sas morte, ea 1916 , Alberto Osiorio ds Castr. deixara oinda inedila a obra aPlantas Cteis da llha do Timors as aotas concernentes a uma obea projectade, mas aio inclaib. a qao dera o titalo do a Bistoria da Sociedade Portagaesa a ladia nos Sicalos XII e XIII,.

Pertenceado a gerapáo de Antionio Sobre, do Eageaio de Castro e de 11 - perto de Otiveira, pablicas en Coimbra - jornal literário a Bocenia Sovas onde manleve una vipa polemica com • grapo literário chefiado pelo antor dos coariv tos. Seas pares nessa revista foran Aatiaio Sobre e Alberto de Oli veira. Foi amig- pessoal do poeta simbolista Camilo Peseanha que, como ele, no ultramar se realizara como grande poeta.
I saa personalidado do escritor quo se estendea, como foi dito, ao eaior espaco portagaćc, onde fal adairado e aearinha do. aa impedia - eniversalismo da obra qae nos legos. Amigo o admirada por eseritores como a Condessa do Soailles, Mistral. Reay do 6 armonte - Rabea Dário, qae the cousagroa an capitalo ond dos ceas firros, Ilberto Osirio de Castro represeata un dos pantos cimeires an literatura portagnesa coatempordaca.

Por isse - lembrames aqui, apontando o eran un dos oxemplos mais marcantes do escritos motropolitano, que se realizon atraves de un lirismo th qae a imagetica e a inspiracalo al tramarieas estiverza sempre presentes. bsto, para alem das obras de caracter ciestifice qae a altramar dedicon, como investigador.

\section{DIAS} PODE O HOEEN VIVER

Seguado afira am , ciestista suviéucus, o hunem pudo Wri, perfoitamedto a Lua daiat. 700 dias, couma fortaioza conoIruida cou a lo lebar para o pro teger das raviacoeos.

A n iliela voiu a iame quendc - Lubar-14 - a mais rocente conda ludar rasa - ontrava da segunda motade do p-rcurso para o entélite terrestre, -oade dereria chegar a a aite a eguinte, ce bo u que atbagora a io baja id. formaçio oficial subre o pro gresso do onger he.

Eutretanto. U. R. S. S. Ian. ço - sez 211." satélite da série Come- - anuacion a gencis Tass.

\section{nisรIONÁRIo INTINADo A SAIE DA INDIA}

Ful intimado a cair da India, no prazo de tros amonas, o nis vioniri ealoieo expanbul, V, cente Ferrar, eegando se a a cia ofic a'mente.

Aqu-ie sacerdute dirigia um. misane nos meios rarais de $\mathrm{N}$. stk, a 160 quilometres nortente de $k-m b \cdot m$. E arusado de tor distribulde $\bullet \cdot m$. las a os eampone us, exorceodo, deote =0, c af etaria preja ticial à admiois tracko pablicas. 


\section{As Flores de Coral}

Em 1908 publicou em Díli Flores de Coral que foi o primeiro livro impresso em Timor ( $A$ Voz de Timor, 11/7/1965, p. 4). Esta obra, nas palavras do próprio autor, é a primeira a ser publicada pela Imprensa nacional de Díli - Díli, Timor-Leste. Este livro foi dedicado ao Fialho de Almeida, e dele são impressos 72 exemplares em papel Song-Kio-Tzo de Cantão, assinados e rubricados pelo autor, 250 são impressos em TCO-TPO - papel pagode de Cantão - e 31 exemplares, também rubricados e numerados, são impressos nos dois papéis mesclados (Goldsteins, 2012, p. 22). Entretanto, Flores de Coral é - na opinião de Rui Martins (in blog Tertúlia Bibliófila, $24 / 5 / 2012$ ) - valorizada pela sua

extensa dedicatória autógrafa do autor, que foi juiz de direito em Dilli, capital de Timor, a João Baptista Gregório de Araújo, inscrita no anterrosto, e que reza: «Ao Senhor Advogado João Baptista Gregório de Araújo, em prova de consideração, e de agradecimento pelos informes que me deu para este livro da sua formosíssima terra, e lembrança affectuosa do autor. Lahane, Março 1, 1910». Tem no fim a seguinte justificação editorial: 72 exemplares, numerados e rubricados pelo autor, em papel branco Song-kio-tzú de Cantão, 257 em papel amarelam Tço-tzu, ou papel pagode de Cantão, e 31 nos dois próprios mesclados, e também numerados e rubricados. Acabou de se imprimir esta obra, para o autor, na Imprensa Nacional, em Dilly, ilha de Timor, arquipélago de Sunda, aos 31 dias de Dezembro de 1909, sob a direcção tipográfica de Francisco Maria Jorge, de Nova Goa, India portuguesa e José Maria Ribeiro, de Baneau, Ilhas de Timor. O presente exemplar é o n. ${ }^{\circ} 176$ dos $257 \mathrm{em}$ papel amarelo, assinado pelo autor. Falta-lhe a primeira folha de guarda, tem algumas manchas de humidade, leve e ocasional trabalho de traça nas margens brancas verticais das folhas 241 à 256 , sem ferir qualquer letra e as últimas folhas com minúsculos restauros. Não obstante o que fica dito, muito bom miolo. Segundo Inocêncio, XX, pág. 321, «O livro "Flores de Coral" é, com efeito, precioso e as notas que o enriquecem dão -lhe extraordinário relevo e até pela abundância de esclarecimentos etnográficos e filológicos, pondo-nos em relação, pelos seus vastos e úteis estudos, com os eminentes literatos que têm estudado profundamente os assuntos orientais, não esquecendo o que devem às "Peregrinações" de Fernão Mendes Pinto».

De um modo geral, o livro Flores de Coral se inicia com a sua viagem de ser poeta e de ser aventureiro na terra da gente timorense, como afirma o seu próprio verso a seguir:

\footnotetext{
Dispersos pelos mares,

Alguns dias de luz me alvorejaram.

Ondas d'oiro no nácar dos luares

O meu sonho embalaram.

E em flores de coral, sob os palmares,

Rolaram-no, e passaram

(Castro,1909:295).
}

Mas que longo cavaco pela noite fora, para quem tem de madrugar com o baile completo, cheio de performance do tropical sereno. Sabendo que a vida do

${ }^{5}$ Fonte: http://tertuliabibliofila.blogspot.com/2012/05/palacio-do-correio-velho-leilao-de.html (acesso em $12 / 3 / 2014)$ 
poeta daquela era estava dispersa pelos mares adentro e quando chegava a terra verde e vermelha começou a sentir a voz dos passarinhos e o som das grandes árvores batidas pelo vento. E quando chegava a noite, o poeta Alberto Osório de Castro lançava o seu olhar e observava tudo o que se passava no seu redor. Por isso que os seus olhos estavam sempre atentos a suprema maravilha da noite timorense, pelo que de Lahane começou a brilhar a paixão pelo esplendor da noite serena e suave que dava mil sensações. Foi assim que o poeta aclama sua profunda saudade no "Fúlan naróma" e a infinda noite opalescente fazia a poesia falar, a razão pela qual Castro disse que "mas isto é poesia" (Castro, 1996, p. 96).

Quanto a prova científica que as Flores de Coral representam, dizia Camilo Pessanha:

Constituem as Flores de Coral a mais cabal demonstração de que não são antinómicas a poesia e a análise científica; e parece que é propositadamente para dar corpo a essa demonstração que o poeta, procedendo contrariamente a todas as tradições; desvenda, no curioso apêndice à sua obra poética, os segredos da génese desta, que lhe justificam a orientação e facilitam a exegese. Não lhe basta atribuir a cada uma das suas composições duas datas, indicando uma o lugar e o momento da (...) impressão do exterior que inspirou, e declarando a outra o lugar e o instante em que (...) a transformação perfeita desse germe se realizou (...); ainda em cento e cinquenta páginas de compacta impressão, familiariza o leitor com os diversos factores de que a sua obra é o resultado, faz menção das suas próprias características étnicas, dos misteriosos e remotos atavismos que influenciam o seu trabalho mental; alude às suas próprias leituras, às predilecções do seu espírito, às suas viagens, esforça-se principalmente por dar a conhecer o meio exótico em que surgiram as Flores de Coral e que tanto contribuiu para lhes dar cor (Pessanha, 1910, p. 109; obs. cit Braga, 2014, p. 297).

É certo que as notas científicas, técnicas e artísticas cujas provas descritivas sobre apontamentos etnográficos e a formação da "pequena casa lusitana, doçura do lar colonial, na compreensão da alma dos naturais” (Castro, 1934, pp. 12-13), ou seja, domesticação da lusitaniedade no oriente em literatura de exotismo que conduziu o Camilo Pessanha a reflectir propositadamente acerca do lugar de conexão entre a ciência e a poesia que se norteia nas Flores de Coral. A este propósito, Gustavo Rubim (1993, p. 99):

(...) importa sublinhar de que maneira as Flores de Coral representam, na leitura de Pessanha (...) uma desarticulação daquela antinomia [entre ciência e poesia] e, nessa medida, um outro entendimento da modernidade. A razão encontra-se, não apenas no gesto pelo qual Osório de Castro 'familiariza o leitor' com tudo o que possa explicar o que hoje se chamaria o seu 'processo criativo', mas também na autonomia que essa explicação adquire no corpo do livro, distanciando-se do seu conteúdo especificamente literário.

\section{Continua o crítico literário,}

Se a heterogeneidade do livro de Osório de Castro constitui, por si mesma, 'cabal demonstração' de uma falsa antinomia, no sentido em que mostra, dá a ver ou põe sob os nossos olhos (...) uma outra relação entre o poético e o científico, já a orientação intencional a que o 'apêndice' obedece, do ponto de vista estético, levanta problemas que (...) afloram na retórica da sua 'notícia' (Rubim, 1993, pp. 100-101). 
Sendo assim, a ciência e a poesia continuam a cruzar-se entre si, como se nota em alguns trechos das Flores de Coral:

Este vale profundo de Lahane nos montes de Díli, de altas encostas de xistos avermelhados ou cinzentos, incrustados, estriados, atravessados de quartzo, e cuja ribeira deriva sob rochas negras eruptivas, basálticas, creio, sobre rochas metamórficas de estrutura xistóide, em que os elementos claros ziguezagueiam e se entranham em arabescos angulares nos elementos escuros, mais regularmente dispostos; sobre pedras silicosas, granitos mesmo, é sempre para mim novo e belo. Não me canso de admirar a graciosa e alta vegetação da ribeira, a vida resistente das epífitas, pequenas urnas cor de casulos de seda das Dischidia rafflesiana, orquídeas em flor, de um odor de donna, de uma fragrância de mel e de ananás maduro, as grandes ribas a prumo vestidas de Polypodium imbricatum, a barba glauca de deuses marinhos dos Platycerium grande, o verde abraço dos Philodendron por troncos e grutas (Castro, 1909, pp. 449-450).

Tudo isso é uma realidade constante mostrada por um admirador exterior que procurou estabelecer um nexo poético com a ciência, isto é, Ruy Cinatti que na sua leitura vê que nas Flores de Coral "Não se pode ir mais longe na descrição, ao mesmo tempo poética e exacta, científica e literária, provando-se, uma vez mais, que o conhecimento poético supera o conhecimento científico quando aquele afina pelo tom da verdade objectiva" (Cinatti, 1992, p. 561). É óbvio que Flores de Coral foi uma "obra de colonização ou é científica, ou não é nada, ou, quando muito, uma tão só miserável exploração das populações primitivas" (Castro, 1909, p. 561), continua a ser uma referência exemplar para muitos que queiram conhecer Timor e a sua gente.

\section{"FLORES DE CORAL" \\ O primeiro livro impresso em Timor}

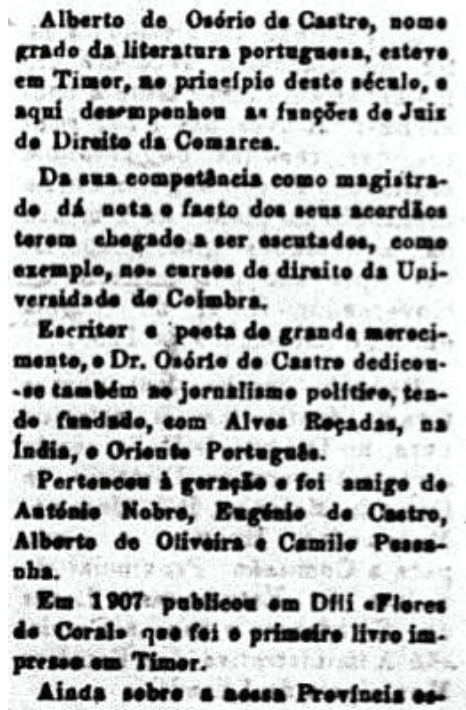

erovep̣ o livro allha Verdo e Varmdlhas - deison inddita a obra ePlantas Útris da Tha de Timors, trabalko eeto do grande valer botlaice.

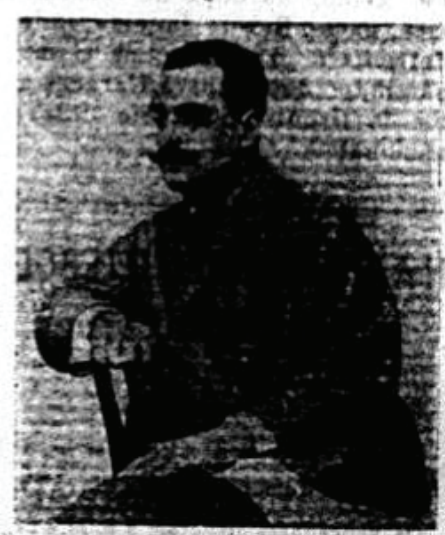

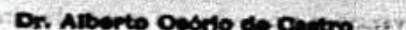

Figura 1 - Flores de Coral: o primeiro livro impresso em Timor (A Voz de Timor, 11/7/1965, p. 4). 
Nas Flores de Coral encontram-se também a "descrição feminina" de Alberto Osório de Castro, formatada por um "episódios e epigramas" de vida de algumas nonas:

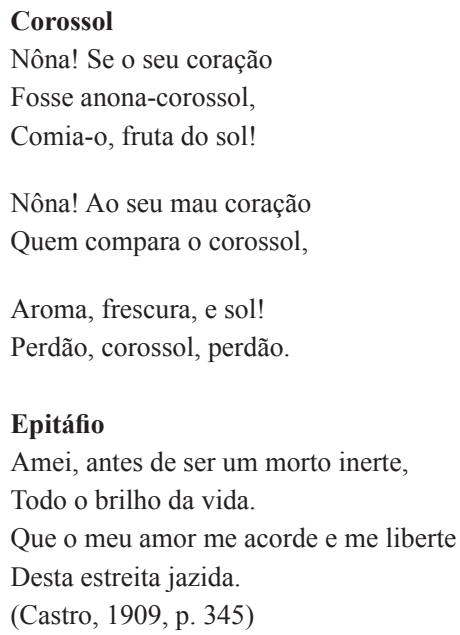

A descrição feminina apresentava uma passagem de amor entre uma "Nôna" com um malae, que aconteceu antes de ser morto inerte. Isto é, um tom idêntico da emoção daquele que presenciou a vida real daquela época. E assim que, dizia o poeta,

Foi o que amei da terra:

a forma feminina, e as formas vegetais.

A morte não me aterra.

É apenas começar outros sonhos vitais.

(Castro, 1909, p. 347).

Que faz a vida florescer em todas as circunstâncias do tempo, e continuou o poeta que "se clemente comigo, deixa-me ir para ti serenamente, num suspiro profundo" (Castro, 1909, p. 348).

\section{A ilha verde e vermelha de Timor}

Publicou em 1946, a "Ilha Verde e Vermelha de Timor" e foi reimpresso em 1996 pelo Editor Cotovia. Esta obra foi uma das descrições tão exóticas que conduziu a sua pessoa como "positivamente" enfeitiçada pela "maravilhosa terra de Timor". As suas minuciosas observações sobre a paisagem e a gente de Timor, "cruzam-se, nas suas impressões sobre a Insulíndia, a condição social de juiz e o léxico prolixo do simbolismo, mais a sabedoria científica de um amador instruído em áreas que iam da Biologia à Etnologia, da Geologia à Antropologia, da 
Botânica à Geografia, somando-lhes o conhecimento das literaturas. O resultado é um relato maravilhado trespassado de referências inerentes a essa erudição, rendendo-se perante paisagens, gentes e bichos" (António Loja Neves, Expresso, 1/6/1996). É uma obra literária histórica de colonização portuguesa ou é científica ou não é nada que revela a beleza tropical da ilha e os seus habitantes. É uma obra para reler a etnografia de Timor como "alcance prático" do reconhecimento nacional (Cf. Sousa, 2014).

A publicação do livro "Ilha Verde e Vermelha de Timor" está integrada na colecção de "Insulíndia Portuguesa" . Este livro foi publicado com Despacho de S. Ex.a o Ministro das Colónias, de 12 de Março de 1943, foi impresso pela Editorial Ática, Rua das Chagas, 23 a 27, Lisboa, tendo ocorrido a composição e impressão durante o mês de Junho de 1943. A chancela é da Divisão de Publicações e Biblioteca da Agência Geral das Colónias. Aparece, como vemos a seguir, dedicada a Hernâni Cidade.
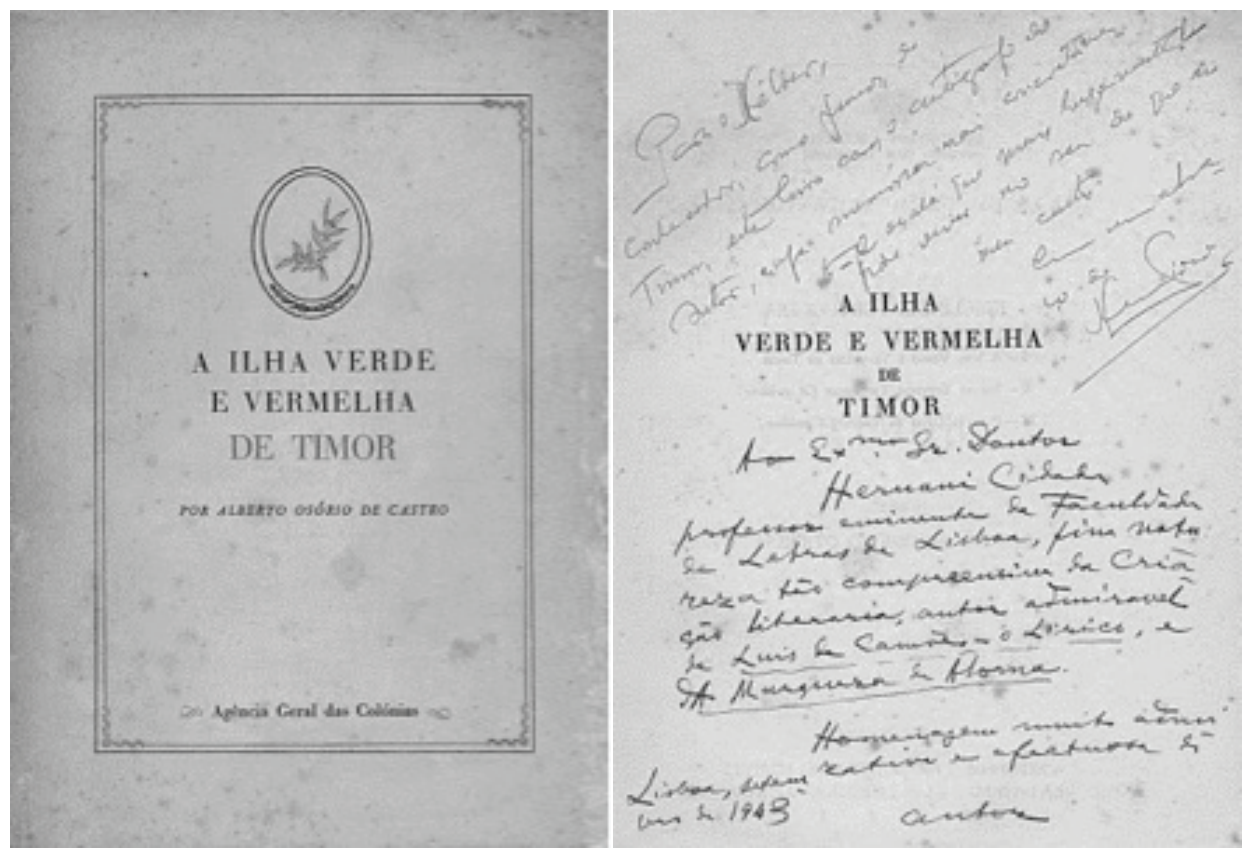

Figura 2 - Dedicado ao Hernâni Cidade ${ }^{7}$

\footnotetext{
${ }^{6}$ Neste livro encontra-se publicado os "Breves estudos timorenses e Plantas úteis de Timor" publicado pelo próprio autor em 1868 .

${ }^{7}$ Fonte: http://kaligraphias.blogspot.com/2010/01/ilha-verde-e-vermelha-de-timor-por.html (acesso em 28/4/2014)
} 
Na Ilha verde e vermelha de Timor, Alberto Osório de Castro, fez declaração "curiosita naturale" sobre a Timor - especificamente a Díli, e com espírito fantasioso classifica esta terra como lugar do "sonho dos homens" e nem "falta um canguru" porque a "pequena méda" o representa:

A minha primeira impressão de Timor, no desembarque em Díli, foi a de que pisava de novo a terra da Índia do Conção, do solo, aqui de xistos e suas argias, lá de laterites, a mesma flora, a mesma tez da gente. Apenas aqui mais macarada a luz, mais docemente aproximada dos sonhos dos homens A breve fauna de Timor não é já, pode dizer-se, a da Índia, como é a de Samatra, da Península Malaia, a da Java, mas a da Australia vizinha, tão diversa. Nem falta em Timor um canguru, a pequena méda (Castro, 1996, pp. 20-21).

O sonho dos homens reflecte-se ao sonho do próprio poeta, pois a partir desta terra longínqua que revive a sua infância. É muito natural que a maravilhosa terra de Timor enfeitice positivamente a sua alma poética, e com essa maravilha natural que se realizou "o sonho dos seus catorze anos de pequeno beirão enfermiço, encantado a traduzir pouco mais ou menos a obra do naturalista Wallace sobre o Arquipélago Malaio que vinha na revista Le Tour du Monde. Em Timor vivera Wallace, também um dia eu lá havia de ir! e lá fui”" (Castro, 1996, p. 66).

O "sonho dos homens", assim por dizer, é um sonho de paixão pela natureza exótica, tudo é original e intangível. Parece que o seu sonho foi realizado quando o poeta descreve a maravilhosa do "alto do cume de Gugulêur, à direita do cominho para Daro-lema, a planície do Lóis norteada pela branca de areias, verde-clara de arrozais e pradarias. O monte piramidal de Atabai (1975 metros) cobrido pela névoa da manhã e da tarde, e a vista perde-se até ao pico holandês de Fialáran, no extremo horizonte fronteiro. (...) À esquerda marmoreia-se de tons róseos e o espigão de Cailaco (340 metros), de faces a prumo, Encurva-se para sul, na fronteira de Manufahi, a garra adunca do Ramelau (2950 metros de altura, segundo a carta de $\mathrm{S}$. Gago Coutinho), o mais alto píncaro do território, e à direita o Darulau, de 2322 metros de altura para trás dessa cordilheira é o mar de timor violento, o grande vento que vem do Scrub da Austrália, perpetuamente em flor (Ibidem, pp. 48-49). Todavia, partindo da viagem por montanhas de Timor o poeta mexe o seu cérebro pensante a imaginar as serras de Coimbra, de Mangualde, e a serra de Estrela (irmã da montanha de Ramelau, de então, o mais alto de Portugal).

A natureza de Timor é tão rica e bela que conduz o sonho dos homens ao fim do mundo, viajando na frescura das ribeiras enfeitadas pelas cores de gaboeiras até à divina costa verde, como aclama Alberto Osório de Castro em alguns versos do seu poema Reisebilder (Castro,1996, p. 22): 
E eis-te no fim do mundo,

Costa verde e vermelha de Timor!

Mas que divina, extraordinária cor,

A do teu céu, a do teu mar profundo!

É d`oiro a manhã de Dili.

Trilla tão lindo o corlilli.. ${ }^{8}$.

$\mathrm{Na}$ frescura das ribeiras.

Murmuram perpetuamente

À verde sombra virente

Das gaboeiras ${ }^{9}$

Para parafrasear a inspiração do poeta, recorre os versos do poema Natureza Infeliz de Vicente Paulino que reflectem criticamente a realidade de Timor contemporâneo:

A espuma do pó sobrevoa na beira das estradas de Díli

faz os vivos a morrer sem lágrimas.

Mas que castigo esse, d'oiro cidade de Díli,

onde as cinzas de máquinas fazem gentes algemas.

As gaboeiras destruídas

fazem crescer estradas de água.

Quando as nuvens choram mingadas,

Caicoli e Colmera inundadas

Os palácios livrem de água.

Praia dos coqueiros era bela

Agora, é feia e cheia de nuvens do pó

sem sombra da árvore, a vida da gente é nula

É o retorno do reino do pó

As gaboeiras destruídas

Timor seca sem frescura das estradas

A verde alma da gente fica do lado

Pois, a vermelha nada está do lado

Assim, não há sombra que acalma

É um castigo infernal da alma ${ }^{10}$

Ruy Cinatti teve um gosto particular pelo livro Ilha verde e vermelha de Timor de Alberto Osório de Castro. Foi este livro que o inspirou a desenvolver o seu trabalho de investigação científica acerca a colónia de Timor. Assim descreve Cinatti (1992, p. 560):

${ }^{8}$ Pequeno pássaro dos arvoredos das ribeiras de Timor

9 Termo timorense para uma espécie de palmeira típica

10 Paulino, Vicente. 2014. "Natureza Infeliz", in Emarculturas - http://emarkulturas.blogs.sapo.tl/ (acesso em 15 de Outubro de 2015). Este poema é publicado pelo autor em sua obra "Leituras do mundo e da natureza, poemas" (2018, p. 80). 
O livro de Osório de Castro, além de ser exemplar único da história literária e de se assemelhar por estes e outros motivos à obra de Fernão Mendes Pinto, há-de ficar na literatura da especialidade como sendo a primeira contribuição moderna da fitografia timorense. (...) O amadorismo científico e a falta de elementos informativos, longe de prejudicar a estrutura da obra, estimularam todas as faculdades da inteligência do autor, obrigando-o a aplicar a um mundo ignoto as várias facetas do seu poderoso talento descritivo. Qualquer coisa que se lhe depare é descrita com aquela frescura e novidade de quem inventa palavras certas para um conjunto de imagens que se experimentam pela primeira vez, sendo para considerar, sob um aspecto filosófico e político, que em 1909 tenha sido escrita por um poeta a seguinte afirmação: 'Hoje a obra de colonização ou é científica ou não é nada'.

O elogio feito pelo Ruy Cinatti a Alberto Osório de Castro foi um acto de reconhecimento entre os conhecidos e os amados no seio da comunidade literária. Entende-se, entretanto, $A$ ilha verde e vermelha de Timor - no contexto de Teoria da Literatura - é um peculiar livro de viagem, escrita em prosa poética, cheia de informações exaustivas sobre a ilha, a sua paisagem e as suas gentes. Muitas vezes, considera-se como uma obra de múltiplos aspectos em que avulta a ânsia de sair de um meio fechado com perspectivas globais. O que parece oportuno é indicar algumas directrizes que podem contribuir para a reflexão sobre a literatura de Timor e/ou timorense. Pensa-se que são válidas quaisquer que sejam os dados históricos com a condição evidente de serem aplicados pela forma e na medida em que o próprio meio permita desenvolver os traços literários timorenses.

Não deixando, porém, de apresentar algumas linhas enchidas pelas notas históricas sobre o Lifau, a primeira capital da possessão portuguesa em Timor até 1769, e "após um longo assédio das indígenas" escreve Pinto Correia, em notas a páginas 338, "trocámos Lifau para Díli” (Castro, 1996, p. 24). Mas, para o reconto destes lamentáveis dias dos meados do século XVIII em Timor, veja-se a obra que o inteligentíssimo e notabilíssimo do governador da Colónia, Afonso de Castro, apareceu com sua obra As Possessões Portuguesas da Oceânia, descrevendo lés a lés sobre a terra do sândalo. É uma das melhores obras da histografia colonial ${ }^{11}$, e que bem merecia uma reedição cuidada, talvez apenas modernizada, é a única obra de tão firme pensamento e crítica, e única na documentação que reúne todos os elementos etnográficos da ilha do sândalo. Alberto Osório de Castro na sua obra Flores de Coral aludiu também o primeiro antropólogo português que chegou a Timor neste enunciando:

Mas chegou a Timor com o novo governador (...) o primeiro antropologista português, o Sr. Capitão Fonseca Cardoso (...). Portugal vai dever ao Sr. Capitão (...) o primeiro estudo científico das popu-

${ }^{11}$ De referir ainda que os três volumes da obra de Luna Oliveira, Timor na história de Portugal, publicada pela Fundação Oriente em 2004; Timor Português, de Hélio Esteves Felgas, publicada pela Agência Geral do Ultramar, em 1956; Timor Português 1515-1769: Contribuição para a sua história, de Artur Teodoro de Matos, monografia de licenciatura da Faculdade de Letras da Universidade Lisboa. 
lações do seu território da Oceania (...), de tanto e coronal interesse para a nossa politica colonial na Insulíndia (e quando teremos verdadeiramente uma meditada, e arrazoada, e seguida política colonial?) (...). É bem desagradável que (...) o livro de Mr. Maugham, Portuguese East Africa, diga de nós: 'l'Afrique Orientale Portugaise, région dont les Portugais n'étudient guère les populations' (Castro, 1909, pp. 409-410).

Contou ainda que por vezes é no tribunal de Timor um grave problema a nomeação do intérprete, pois as línguas faladas pelos nativos do território são, por natureza, incompreensíveis de uma região para outra. Sendo assim, recorreu-se sempre alguns meios para facilitar o seu serviço e a sua comunicação com a população. E para a sua documentação, o poeta Alberto Osório de Castro, apresentou em "As ilha verde e vermelha de Timor" (1996, pp. 91-92) as línguas faladas em Timor pelas respectivas comunidades étnicas.

\section{Epílogo}

Se a gente quiser conhecer mais poemas que falam de Timor e do mundo oriental, terá que ler não só Flores de Coral, mas também Sinal da Sombra, onde aquela tópica se pode encontrar em meio a uma colecção de líricas persas, japonesas e chinesas. A este convite, Duarte Nuno Drumond Braga (2014, p. 304) adverte que "em Flores de Coral há que olhar, para o que o livro faz, para além do que o que diz, uma vez que historicismo e didactismo, ainda que possuam efeitos directos no modo de organização da obra, apontariam sobretudo para o que o texto diz. Assim, a datação dupla, por exemplo, parecendo encerrar o poema na sua própria genética, patenteia, a um mesmo tempo, o trânsito interno à escrita, num dinamismo que ecoa os trânsitos biográficos do autor" com "a natureza da intertextualidade literária própria" (Braga, 2014, p. 305) nos degraus do tempo em que formou os versos sobre à "pátria perdida" na terra exilada com gente portuguesa de raça mista que vive da própria vida com experiências contaminadas pela cultura local. É uma "influência do império nas letras" e de "de filiação pré-lusotropicalista (...) esta impregnação espiritual em outras raças, que é tão nossa (...) [,] só se consegue pela compreensão das almas das outras raças. E é pelas letras que hoje é permitido compreender até ao mais íntimo a alma velada dos povos coloniais, em contacto com a nossa alma" (Castro, 1936, p. 414).

Após alguns anos de servir a sua pátria portuguesa nas terras orientais, Alberto Osório de Castrou regressou a Portugal como "vitorioso", pisando de novo a praia lusitana para dar

\footnotetext{
“à língua portuguesa contemporânea o esmalte exótico que desde a época clássica havia perdido. (...) todo este mundo esplendoroso que poderia ser a herança da genealogia parnasiana do Poeta, ele o viveu e sentiu em realidade e sonho, sobrepondo-se, pela comoção da sensibilidade histórica, pela verdade dos motivos, aos ditames convencionais da sua escola" (Raposo, 1936, pp. 53-54).
} 
Alberto Osório de Castro morreu discretamente. Foi uma morte despercebida entre os conhecidos, porque não era um poeta de tertúlias literárias nem de grupos políticos (embora pertencesse ao Partido Regenerador e assumiu o cargo ministro da justiça no governo de Sidónio Pais); por isso, a sua morte passou pouco menos que despercebida dos jornais e completamente ignorada do público. Todavia, foi não só um grande poeta como também um português do mais elevado patriotismo e "um poeta ocidental verdadeiramente português que se deixou vencer pelas mais belas e estranhas seduções dos mares e terras orientais que sempre viveu nos seus versos como nenhum outro poeta ocidental" (Osório, 1946, p. 9). Foi um

\begin{abstract}
“(...) admirável intérprete das terras e das sensibilidades que formam o Império Português. Ele foi na verdade o maior dos nossos artistas - não quero dizer: coloniais - que têm exprimido a expansão da alma portuguesa no Mundo e a integração nessa mesma alma das riquezas emocionais dos povos que colonizámos e com quem convivemos. Um artista que com talento novo e superior continuou os grandes nomes do século de oiro - um Fernão Mendes Pinto da sensibilidade (Caetano, 1946, p.3)."
\end{abstract}

Augusto da Costa (1946, pp.129-130), por sua vez, considerou Alberto Osório de Castro como um dos maiores artistas portugueses que tem exprimido a expansão da alma portuguesa no Mundo e a integração dessa mesma alma das riquezas emocionais dos povos colonizados com quem conviveram. Afirmava ainda que ele foi "Um artista com talento novo e superior" e o seu nome contínua a ser grande na era do "século de ouro". Foi um

\begin{abstract}
"poeta de mais complexo e completo sentido português. É estrita obrigação de uma revista que tem por título 'Mundo Português', título que representa um programa e uma consciência de grandeza do génio nacional, relembrar na hora da morte deste grande Poeta como toda a sua obra está ligada à vida imperial do povo português, à sua tradição histórica como à sua presente renovação" (Osório, 1946, p. 8)."
\end{abstract}

Em sua memória, o estado português designou uma rua com seu nome: Rua Alberto Osório de Castro, no concelho de Oeiras.

Finalmente, para a conservação dos documentos pessoais dos grandes escritores e poetas portugueses, o poeta António Osório entregou à Biblioteca Nacional de Portugal (BNP), as "Cartas da poetisa brasileira Cecília Meireles a Maria Valupi e de Camilo Pessanha a Ana de Castro Osório", incluindo outros documentos doados "constam duas cartas manuscritas de Camilo Pessanha a Ana de Castro Osório, o dactiloscrito da carta-poema "Dulce querida", dedicada por Cecília Meireles a Dulce de Castro Osório, fotografias do próprio António Osório, de Ana de Castro Osório e filhos, de Camilo Pessanha, de Alberto Osório de Castro" (Agência Noticiosa Lusa, 12/2/2008). 


\section{Referências}

Almeida, C. N. \& Braga, D. D. (2013). Nau-Sombra: os orientes da poesia portuguesa do século $X X$. Lisboa: Nova Veja.

Braga, D.D. (2014). Ao oriente do oriente transformações do orientalismo em poesia portuguesa do início do século xx: Camilo Pessanha, Alberto Osório de Castro e Álvaro de Campos. Tese de Doutoramento, Lisboa: Faculdade de Letras da Universidade de Lisboa.

Castro, A.O. (2004). Obra Poética. Vol. 1, Lisboa: Imprensa Nacional - Casa da Moeda.

Castro, A.O. (1996). A ilha verde e vermelha de Timor. Lisboa: Edições Cotovia

Castro, A.O. (1994). Exiladas. In, Alberto Osório de Castro. Obra Poética, vol. 1, Lisboa: Imprensa Nacional - Casa da Moeda. Lisboa: Imprensa Nacional - Casa da Moeda.

Castro, A.O. (1909). Flores de Coral. Poemetos e Impressões da Oceânia [Últimos Poemas]. Díli: Imprensa Nacional.

Cinatti, R. (1992). Paisagens timorenses com vultos - obra poética. Lisboa: Imprensa Nacional-Casa da Moeda.

Castro, A.O. (1936). A Influência do Império nas Letras. Alta Cultura Colonial, Discurso Inaugural e Conferências, Lisboa: Agência Geral das Colónias, Divisão de Publicações e Bibliotecas, 401-416.

Castro, A.O. (1934). Alma Colonial. O Mundo Português, volume 1, n. ${ }^{\circ}$ 1, 11-13.

Caetano, M. (1946). Palavras do Prof. Marcelo Caetano, Ministro das Colónias. Diário da Manhã, [Suplemento "Cultura", 3], Lisboa.

Costa, A. (1946). Artes e letras coloniais - a morte do poeta Alberto Osório de Castro. Boletim Geral das Colonias, vol. 22, n. ${ }^{\circ} 250$, pp. 129-130.

Goldstein, Â.R. M. (2012). A representação do oriente na obra poética de Alberto Osório de Castro. Dissertação de Mestrado em Estudos Comparados de Literatura de Língua Portuguesa, São Paulo: Universidade de São Paulo.

Nóbrega, P.P. (2004). Alberto Osório de Castro: incursões pela arqueologia mangualdense. In http://confaoc.no.sapo.pt/conf12.html [texto da conferência proferida a 4-05-2004 em Mangualde aos alunos do $7 .^{\circ}$ ano da E.S.F.A.]

Osório, J.C. (1946). Alberto Osório de Castro, o Poeta do Renascimento Português e Imperial. Mundo Português: Revista de Actualidades do Império, ano XIII, II ${ }^{\mathrm{a}}$ série, n. ${ }^{\circ}{ }^{1}$. Lisboa: Agência Geral das Colónias, 8-11.

Pessanha, C. (1988). Obras de Camilo Pessanha, Clepsidra e poemas dispersos. Introdução biográfica e crítica, Organização e Notas de António Quadros, Lisboa: Publicações Europa-América

Paulino, V. (2018). Leituras do mundo e da natureza, poemas. Díli: Casa Apoema.

Paulino, V. (2011). A imprensa católica 'Seara' e a tradição timorense: 1949-1973. In Silva, Kelly \& Sousa, Lúcio (org), Ita maun alin ... o livro do irmão mais novo - afinidades antropológicas em torno de Timor-Leste, Lisboa: Edições Colibri, pp. 169-182.

Rubim, G. (1993). Experiência da Alucinação: Camilo Pessanha e a Questão da Poesia. Lisboa: Caminho. 
74 | RILP - Revista Internacional em Língua Portuguesa - n. ${ }^{o} 36$ - 2019

Raposo, H. (1936). Tatuagens da nossa Língua. Aula Régia. Porto: Livraria Civilização Editora, pp. 3-64.

Sousa, L. (2014). A etnografia e o seu "alcance prático" no Timor "português" (1894-1917). In Vicente Paulino (Orgs.)., Timor-Leste nos estudos Interdisciplinares. Díli: PPGP-UNTL.

Data receção: 18/06/2019

Data aprovação: 28/10/2019 